\title{
FERTILIZATION IN LILIUM
}

\author{
A DISSERTATION \\ SUBMITTED TO THE FACULTY \\ OF THE OGDEN GRADUATE SCHOOL OF SCIENCE \\ IN CANDIDACY FOR THE DEGREE OF \\ DOCTOR OF PHILOSOPHY
}

DEPARTMENT OF BOTANY

BY

WANDA WENIGER

\section{Private Edition, Distributed By}

THE UNIVERSITY OF CHICAGO LIBRARIES

CHICAGO, ILLINOIS

Reprinted from

The Botanical Gazette, Vol. LXVI, No. 3

September 1918 
moing 


\title{
Tbe University of Cbicago
}

\section{FERTILIZATION IN LILIUM}

\author{
A DISSERTATION \\ SUBMITTED TO THE FACULTY \\ OF THE OGDEN GRADUATE SCHOOL OF SCIENCE \\ IN CANDIDACY FOR THE DEGREE OF \\ DOCTOR OF PHILOSOPHY \\ DEPARTMENT OF BOTANY
}

BY

WANDA WENIGER

Private Edition, Distributed By

THE UNIVERSITY OF CHICAGO LIBRARIES

CHICAGO, ILLINOIS

Reprinted from

The Botanical Gazetre, Vol. LXVI, No. 3

September 1918 
Digitized by the Internet Archive in 2017 with funding from

University of Illinois Urbana-Champaign Alternates 


\section{FERTILIZATION IN LILIUM}

CONTRIBUTIONS FROM THE HULL BOTANICAL LABORATORY 243

WANDA WENIGER

(WITH PLATES XI-XIII)

\section{Introduction}

The cytological phenomena of fertilization have been studied with greater detail in the gymnosperms than in the angiosperms. This paper is the result of an attempt to discover whether there is a similarity between the process of fertilization as already described for gymnosperms and that of angiosperms. Lilium has long been the type used in the study of fertilization in the classroom; it was chosen for the subject of study in this case because it lends itself particularly well to cytological work. The writer is indebted to Dr. C. J. Chamberlain for the suggestion of the problem and for his helpful assistance throughout the progress of the work.

In Pinus (1, 3, 5, 7, 8), Tsuga (14), Juniperus (18, 19), and Abies (I2) evidence has been brought to bear upon the fact that no fusion of the male and female chromatic substance takes place.

Blackman ( $\mathbf{r}$ ), in 1898 , described the cytological features of fertilization in Pinus silvestris. While the outlines of the 2 sexual nuclei are still visible, the chromosomes are found in 2 separate clumps; and even on the spindle fibers of the first division they can be distinguished into 2 groups. After a longitudinal splitting the half chromosomes fuse together in the telophase of the division.

Chamberlain's (3) account of oogenesis in Pinus Laricio includes figures of the male and egg nuclei. He states that after the male pronucleus is within the oosphere nucleus the chromatin of the 2 pronuclei appears as 2 distinct masses in the spireme stage. "Perhaps segmentation of the 2 spiremes occurs while they are still separate." In Tsuga canadensis MURrill (I4) reports 2 sets of chromosomes distinct in the equatorial region of the first spindle. 259]

[Botanical Gazette, vol. 66 
Miss Ferguson (7), in her first paper on Pinus Strobus in I9or, finds that the 2 chromatic groups are distinctly recognizable at the time of the segmentation of the spiremes, and can still be clearly made out during the early development of the chromosomes, but not as late as the equatorial plate stage. "There is never any fusion, as ordinarily understood, of the male and female nuclei." In her second paper on Pinus Miss Ferguson (8) describes the longitudinal splitting of the 24 chromosomes on the equatorial plate. According to NORÉN $(\mathbf{I} 8, \mathbf{1 9})$, the essential features of fertilization in Juniperus communis are similar to those of Pinus.

A very detailed account of fertilization is given by Hutchinson (I2) for Abies balsamea. Two groups of chromatin at the micropylar end of the egg nucleus, one male and the other female, become separated into i6 chromosomes each, and these pass on to the spindle fibers. The 2 spindles in the metaphase fuse, and the chromosomes are arranged to form $\mathrm{x} 6$ pairs, each pair forming a $\mathrm{C}$, in which the 2 chromosomes are twisted about each other. By means of a transverse break at the angle of the bent chromosomes each pair forms 4 segments. Of the 64 segments, 32 go to each pole, where in the daughter nuclei they remain very distinct.

Chamberlain counted I 2 chromosomes in Stangeria (4) at the equatorial plate stage of the division of the fertilized egg, while the sporophyte number is 24 . He accounts for the haploid number by assuming the chromosomes to be of a double character, and supports Hutchinson's view of the pairing of chromosomes.

In angiosperms the behavior of the chromatin during fertilization has received little attention. In the majority of cases the statement is made that the nuclei fuse while in the resting condition almost immediately after they come in contact and form a definite resting nucleus, differing only in its greater size from the unfertilized egg nucleus.

GuignARD's (9) paper in 189 I on fertilization in Lilium Martagon contains statements overlooked by most writers. The formation of 2 distinct spiremes in the male and egg nuclei was observed but not figured. No fusion is brought about between the chromatin of the 2 nuclei, even when the nuclear membranes disappear. The segments of each spireme pass on to the equatorial plate, where 
each splits longitudinally. In 1895 MotTer (13) first described the vermiform shape of the male nuclei in Lilium Marlagon. The male and egg nuclei fuse in the resting condition after coming in contact and are figured as forming a resting nucleus. In I 898 Nawaschin (I5) announced the discovery of double fertilization in Lilium Martagon and Fritillaria tenella. The male nucleus that fuses with the polar nuclei loses its spiral form, but the 3 nuclei remain distinct until the prophase of the division. 'The fusion of the 3 nuclei occurs when the numerous chromosomes come together on the equatorial plate. "Fusion occurs, not in the resting stage, as Mottier indicates, but in the prophases of the division, as GUIGNARD first observed."

The motility of the male nuclei is described for Lilium Martagon and Fritillaria tenella by NaWASchin (I6, I7); for the tulip by GUIGNARD (II); and for Lilium Martagon and L. auratum by Blackman and Welsford (2), and Miss Welsford (23). These authors attribute independent motion to the male nuclei.

In Paris quadrifolia and Trillium grandiflorum ERNST (6) finds a striking difference between the fusion of the male nucleus with the egg and that with the polar nuclei. In the former case the fusion is complete, so that a typical resting nucleus is formed. In the latter case the polar nuclei begin to form spiremes even before the male nucleus arrives, and in the group of the 3 nuclei (the 2 polar nuclei and the male nucleus) 3 spiremes are distinguishable.

Distinct maternal and paternal chromosomes were first described for an angiosperm by Miss PACE (2I). She found spiremes in all nuclei of the embryo sac of Cypripedium before fusion took place. The spireme was well formed in every nucleus, and shortened almost enough to segment into chromosomes. "It would seem in this case, that if fusion does take place, there could be no possibility of a fusion of the chromatin, which would certainly divide into chromosomes from the spireme as it is now formed."

Nawaschin (I7) published another paper on Lilium Marlagon in I9ro, again emphasizing the fact that the mature nuclei are capable of movement. He finds that the mitosis of the 2 male nuclei in the pollen tube is characterized at an early stage by sharply differentiated chromosomes, so that the sperm nuclei do not reach 
the resting stage, but remain in the condition characteristic of a telophase.

Recently Sax (22) has investigated Fritillaria pudica. In most cases it is not until the male nucleus and the egg nucleus have completely fused that he finds any appearance of the formation of the spireme. In rare cases, however, the spireme stage is found while the 2 nuclei are still distinct in outline. He believes that the rare appearance of such cases is probably of little significance, since it is probable that these nuclei subsequently fuse completely because no later stages were found in which fusion was incomplete. From the many stages and abundant cases of triple fusion he observed he thinks there is no doubt that the 2 polar nuclei and the male nucleus fuse completely and that the subsequent division is normal.

\section{Methods}

Stages in fertilization were obtained from ovaries of Lilium philadelphicum collected in the field near Osborn, Calumet, and Pine, Indiana, in June and early July, I9r6, at the time when the petals "snapped," and after the petals had fallen. To correlate the time of pollination with stages in fertilization, flowers were brought into the laboratory, pollinated, and kept under bell jars for several days, until fertilization had taken place. In general, it may be said that the petals drop on the third day after pollination, and the style separates from the ovary on the fourth or fifth day. The male nucleus was in contact with the egg nucleus from 60 to 72 hours after pollination.

The material for Lilium longiflorum was obtained from plants grown in the greenhouse. It produced seeds readily, although it is generally reported not to set seed. The male nucleus was in contact with the egg nucleus about I 20 hours after pollination. Of the upward of 500 cases of fertilization observed in these 2 species, the majority showed the male and egg nuclei in contact, with their chromatin in early prophases of the division.

Chrom-acetic-osmic and Flemming's medium solutions were used as fixatives, and the ovaries trimmed so as to permit more rapid penetration of the embryo sacs. Sections were cut го $\mu$ thick and stained with Flemming's triple stain or Haidenhain's iron-alum-haematoxylin. 


\section{Observations}

Upon leaving the pollen tube the male nuclei retain their coiled shape for some time. The egg nucleus (fig. I), with chromatin in a resting condition before the arrival of the male nucleus, remains in this condition, while the male nucleus lies in contact with it. Stages can be found abundantly in which the male nucleus has penetrated the egg and lies adjacent to the egg nucleus, and in which the chromatin of the former is in an early prophase (fig. 2), or spireme stage (fig. 3), while the chromatin of the latter more lightly staining nucleus is in the resting stage. The male nucleus is more or less curved around one side of the egg nucleus and usually measures about $9 \mu$ at its short diameter, while the spherical egg nucleus is ro- $2 \mu$ in. diameter. Soon the male nucleus becomes more rounded, as is shown in fig 4 , where the chromatin in both nuclei is still in the same stage as in fig. 3 .

The chromatin of the egg nucleus is then formed into a spireme (figs. 5, 6); but this spireme was never found to stain as densely or become as regular as that of the male nucleus. The membranes of the 2 nuclei seem still to be in contact at this stage. No fusion of the spiremes takes place, but each is segmented into chromosomes independently. This account agrees with that of GUIGNARD for Lilium Martagon, where no fusion takes place between the chromatic elements of the 2 nuclei.

In the gymnosperms investigated the separate groups of chromosomes formed from the male and female spiremes respectively become oriented on separate spindles, and then the 2 spindles fuse during the metaphase. Whether or not this is true for Lilium has not been determined. The entire process of fertilization in Lilium is an exceedingly rapid one, since the time elapsing between the discharge of the male nuclei and the formation of the 2-celled embryo is probably not longer than 8 hours. Since the contact stage of the 2 nuclei in the prophases of the division is of such relatively common occurrence in preparations made, it would seem that it occupies the greater part of this time, and that for this reason the actual division of the fertilized egg is a very difficult stage to obtain. One very favorable preparation shows this division, with some of the chromosomes still on the equatorial plate and others already 
near the poles of the spindle. Figs. I I, I2, and 13 represent the 3 sections of this spindle, and in fig. 14 the 3 drawings are superimposed and slightly diagrammed. Of the 24 chromosomes present on the equatorial plate, ' 22 are contributed by the male nucleus and 12 by the egg nucleus. The chromosomes are not drawn into the sharp U's and C's so characteristic of divisions in Lilium. The chromosomes come together in pairs in which they twist more or less about each other (fig. I $2 a$ ). Each of the chromosomes of the I 2 pairs then breaks transversely at the center of the ellipse it forms, each pair giving rise to 4 segments. The $48 \mathrm{seg}$ ments in the form of small rods remain paired (fig. I $2 b, c$ ) as they move toward the poles of the spindle. The components of each pair are similar in size so far as could be determined; one segment is male and the other female in origin. In fig. I4 the I 2 pairs of chromosomes are represented, with the 4 segments of a pair indicated by the same number. All segments going to one pole are in black, those to the opposite pole in outline. Chromosomes 8 and I 2 have not as yet come in contact and the transverse break has not yet appeared. This behavior of chromosomes resembles that of the first reduction division in tetrad formation. There is a pairing of chromosomes and a subsequent transverse breaking. The result of the division is not the reduced number of chromosomes, however, but the diploid number, for only a transverse break occurs, and no further splitting.

In the telophase of this division (figs. I5, I6) no further evidence of the pairing of the chromosomes could be observed. It would seem probable that the individuality of the chromosomes derived from the male and egg nuclei would persist. The second division (fig. I 7) of the fertilized egg is in all respects like the ordinary vegetative division in Lilium, with a longitudinal splitting of the characteristic $\mathrm{U}$-shaped chromosomes during the metaphase.

Observations were also made on the behavior of the chromatin during triple fusion. The process occurs much more rapidly and the resulting nucleus divides at least twice before the fertilized egg undergoes division. At the time that the endosperm nucleus divides (fig. 7) the male and egg nuclei are still in the stage shown in fig. 3 or 4 . The 2 polar nuclei, with membranes distinct, are in the resting condition when the male nucleus in the spireme stage comes 
in contact with them (fig. 8). A spireme is then formed in each polar nucleus also (fig. 9), and the nuclear membranes disappear at the point of contact of the nuclei. The lower polar nucleus is usually a little larger than the one coming from the micropylar end of the embryo sac. The male nucleus is at the left in fig. 9.

Segmentation of spiremes occurs so that on the spindle (fig. I9) the chromosomes are extremely long and $U$-shaped. The number of segments is difficult to ascertain, but it approaches the $3^{x}$ number. The division is accomplished by a longitudinal splitting of chromosomes, producing in the anaphase a mass o: long bent segments that cannot be counted with any satisfaction.

There is a striking difference between the first division of the fertilized egg and that of the endosperm nucleus. The former is characterized by shorter straighter chromosomes, a pairing of chromosomes, and a subsequent transverse breaking of ea $\mathrm{h}$ pair to form 4 segments, of which 2 go to each pole. The division of the endosperm nucleus resembles the ordinary vegetative division by means of a longitudinal splitting of chromosomes. The number of chromosomes is $3 x$. Since previous cytological work has not covered the necessary phases, it is possible that the description of the behavior of chromosomes during the first division of the fertilized egg here given may apply quite generally to angiosperms. A longitudinal splitting of chromosomes on the equatorial plate would bring about the same result in that the $2 x$ number of chromosomes goes to each of the daughter nuclei; but the supposition of a longitudinal splitting would not account for the situation described. If a longitudinal splitting should occur before the transverse breaking, rather than a pairing of chromosomes, the resulting number would be 96 rather than 48 segments.

The 3 phases of fertilization, union of cells, union of nuclei, and union of chromosomes, occur in rapid succession in animals, since the reduction division immediately precedes fertilization. In plants the 3 processes may be separated for a longer or shorter period. In the rusts there is a long gap between the union of the gametes at the base of the aecidium and the nuclear and chromosome conjugation. In some of the green algae, such as Oedogonium, the 3 come close together, since reduction follows soon after fertilization. In the brown algae the 3 are also close together, but reduction 
precedes fertilization. In the higher plants cell and nuclear union have been thought to come close together at the beginning of the sporophyte generation, while the chromosome union did not occur until during the reduction division at the end of the sporophyte generation. In Abies, as found by Hutchinson; in Stangeria, according to Chamberlain; and in Lilium there seems to be evidence of a chromosome union at the time of fertilization.

\section{Summary}

I. The egg nucleus is in a resting condition when the male nucleus, in spireme stage, comes in contact with it.

2. Distinct male and female spiremes are formed which are segmented into chromosomes while the nuclei are in contact.

3. On the equatorial plate the male and female chromosomes come together in $x$ number of pairs and divide by means of a transverse break, each pair forming 4 segments. The segments move to the poles in pairs. Of the $4 x$ segments formed, $2 x$ go to each pole of the spindle.

4. The chromosomes on the equatorial plate of the second division of the fertilized egg divide longitudinally.

5. The endosperm nucleus divides at least twice before the fertilized egg undergoes division.

6. A distinct spireme is formed in each of the nuclei of the triple fusion, and the $3 x$ segments are oriented on the equatorial plate.

7. The endosperm nucleus divides in the typical vegetative manner by means of a longitudinal splitting of the chromosomes.

Experiment Station

Agricultural College, N.D.

\section{LITERATURE CITED}

I. Blackman, V. H., On the cytological features of fertilization and related phenomena in Pinus silvestris L. Phil. Trans. Roy. Soc. London B 190 : 395-426. pls. I2-I4. I898.

2. Blackman, V. H., and Welsford, E. J., Fertilization in Lilium. Ann. Botany 27:III-II4. pl. I2. I9I3.

3. Chamberlain, C. J., Oogenesis in Pinus Laricio. Bot. Gaz. 27:268-280. pls. 4-6. I899.

4. - Stangeria paradoxa. Bот. Gaz. 6r:353-372. pls. 24-26. I9I6. 
5. Dixon, H. N., Fertilization of Pinus silvestris. Ann. Botany 8:21-34. pls. 3-5. I 894 .

6. Ernst, A., Chromosomenreduction, Entwickelung des Embryosackes und Befruchtung bei Paris quadrifolia L. und Trillium grandiflorum Salisb. Flora 91 : I-46. pls. I-6. I902.

7. Ferguson, Margaret C., The development of the egg and fertilization in Pinus Strobus. Ann. Botany 15:435-478. pls. 23-25. I90 I.

8. - Contributions to the life history of Pinus, with special reference to sporogenesis, the development of the gametophytes, and fertilization. Proc. Wash. Acad. Sci. 6: I-202. pls. I-24. I904.

9. Guignard, L., Nouvelles études sur la fécondation. Ann. Sci. Nat. Bot. VII. I4: I63-296. pls. 9-I8. I891.

ı. - - Sur les anthérozoides et la double copulation sexuelle chez les végétaux angiospermes. Compt. Rend. I28:864-87I. fig. I9. I899; Rev. Gen. Bot. I I : I 29-I35. pl. I. I899.

I r. - L'appareil sexuel et la double fécondation dans les Tulipes. Ann. Sci. Nat. Bot. VIII. i I :365-387. pls. 9-II. I 900.

12. Hutchinson, A. H., Fertilization in Abies balsamea. Bot. Gaz. 6o:457472. pls. I6-20. I9I5.

r3. Motrier, D. M., Über das Verhalten der Kerne bei der Entwickelung des Embryosackes und die Vorgänge bei der Befruchtung. Jahrb. Wiss. Bot. 3I:I $25^{-1} 5^{8}$. pls. 2, 3. I 898 .

14. Murrill, W. A., The development of the archegonium and fertilization in the hemlock spruce (Tsuga canadensis). Ann. Botany 14:583-607. pls. 3I, 32. I 900 .

I5. Nawaschin, S., Resultate einer Revision der Befruchtungsvorgänge bei Lilium Marlagon und Fritillaria tenella. Bull. Acad. Imp. Sci. St. Petersbourg 9:377-382. I898; reviewed in Bot. Centralbl. 78:24I-245. I899.

r6. - Neue Beobachtungen über Befruchtung bei Fritillaria tenella und Lilium Martagon. Bot. Centralbl. 77:62. I899.

I7. - Näheres über die Bildung der Spermakerne bei Lilium Martagon. Ann. Jard. Bot. Buitenzorg. II. Supplement III. 871-904. pls. 33, 34. I9Io.

18. Norén, C. O., Über Befruchtung bei Juniperus communis. Vorläufige Mitteilungen. Arkiv. Bot. Svensk. Vetensk. Akad. 3:pp. I I. I904.

I9. - Zur Entwickelungsgeschichte des Juniperus communis. Uppsala Universitets, Arsskrift 1907: pp. 64. pls. 4.

20. Overton, E., Beitrag zur Kenntnis der Entwickelung und Vereinigung der Geschlechtsproducte bei Lilium Martagon. Festschrift (NäGELI und KöLliker). Würzburg. I 89 I.

21. Pace, Lula, Fertilization in Cypripedium. Bot. Ga7. 44:35.3-374. pls. 24-27. 1907 .

22. SAX, Kart, Fertilization in Fritillaria pudica. Bull. Torr. Bot. Club) 43:505-522. pls. 27-29. I9 6 .

23. Welsford, E. J., The genesis of the male nuclei in Lilium. Ann. Botany 28:265-270. pls. 16,17 . I9I4. 


\section{EXPLANATION OF PLATES XI-XIII}

All drawings were made with an Abbé camera lucida at table level and Zeiss apochromatic objectives and compensating oculars. For fig. 7 the 8 ocular and $2.0 \mathrm{~mm}$. objective were used, giving a magnification of 1500 ; for the remainder of the drawings the 18 ocular was used with the $2.0 \mathrm{~mm}$. objective, and the magnification was 4000 . All drawings were reduced one-half in reproduction.

\section{PLATE XI}

FIG. I.-Egg before fertilization, with nucleus in resting condition; $\times 2000$; L. philadclphicum.

FIG. 2.-Male nucleus in early prophase; egg nucleus in resting condition; $\times 2000 ;$ L. philadelphicum.

FIG. 3.-Chromatin of egg nucleus more irregular; male nucleus still curved around egg nucleus; $\times 2000 ;$ L. philadelphicum.

FIG. 4.-Male nucleus rounded; $\times 2000 ;$ L. longiflorum.

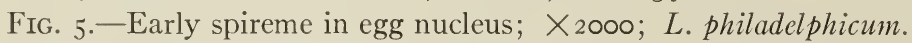

FIG. 6.-Distinct spiremes in male and egg nucleus; segmentation begun; $\times 2000 ;$ L. longiflorum.

FIG. 7.-Endosperm nucleus undergoing division while egg nucleus is in resting stage and male nucleus in contact with it shows a spireme; $\times 750$; L. philadelphicum.

\section{PLATE XII}

FIG. 8.-Triple fusion: male nucleus in spireme stage, upper and lower polar nuclei with chromatin in resting stage; $\times 2000 ;$ L. longiflorum.

FIG. 9. -Distinct spiremes in 3 nuclei of triple fusion; male nucleus at upper left; $\times 2000 ;$ L. philadelphicum.

FIG. Io.-Metaphase of endosperm nucleus; $\times 2000$; L. philadelphicum.

FIG. I 7.- Second division of fertilized egg; $\times 2000 ;$ L. longiflorum.

\section{PLATE XIII}

FIGS. I I-I 3. - Three sections of spindle of fertilized egg in division, showing pairing of chromosomes, transverse break, moving of pairs to the poles; $\times 2000$; L. longiflorum.

FIG. I4.-Diagram of division of fertilized egg, made by superimposing figs. II-I3; the I 2 pairs of chromosomes are represented, with 4 segments of a pair indicated by the same number; segments in solid black go to one pole, while those in outline go to the other pole; chromosomes numbered 8 and I 2 have not yet paired or segmented.

FIG. I 5.-Early telophase of first division; $\times 2000 ;$ L. longiflorum.

FIs. I6.-Late telophase of first division; $\times 2000 ;$ L. longiflorum. 

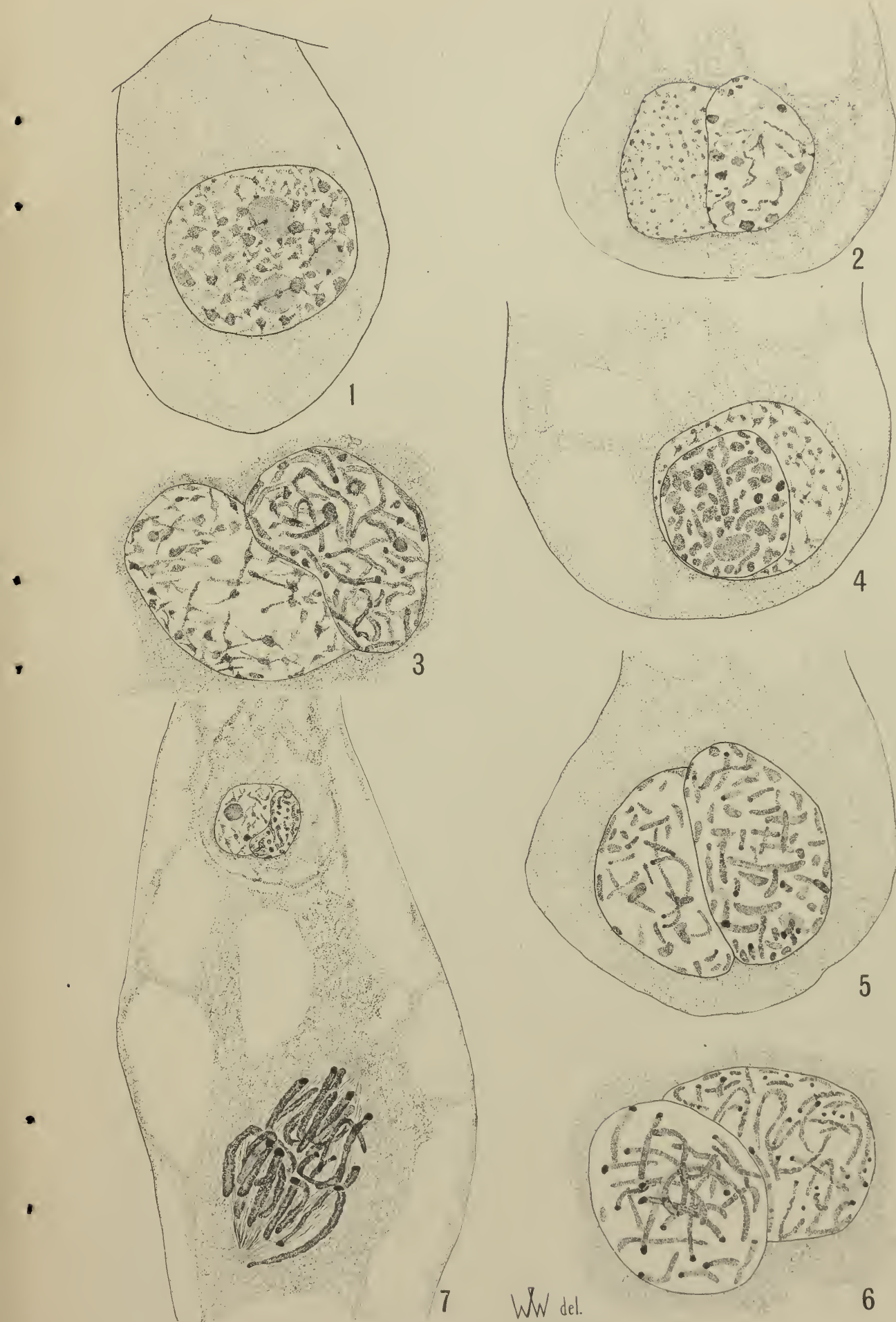

WENIGER on LILIUM

6 


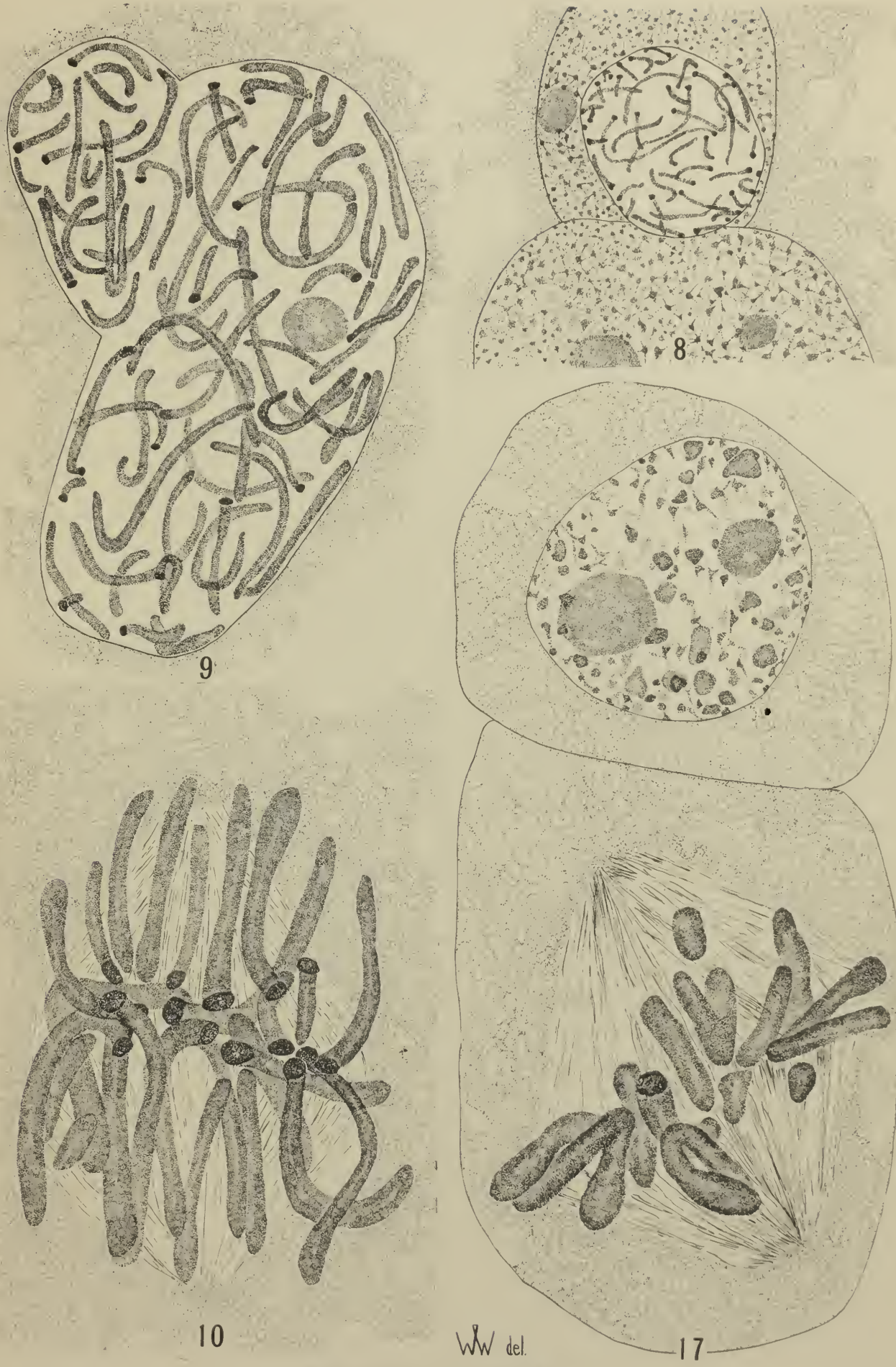

WENIGER on LILIUM 

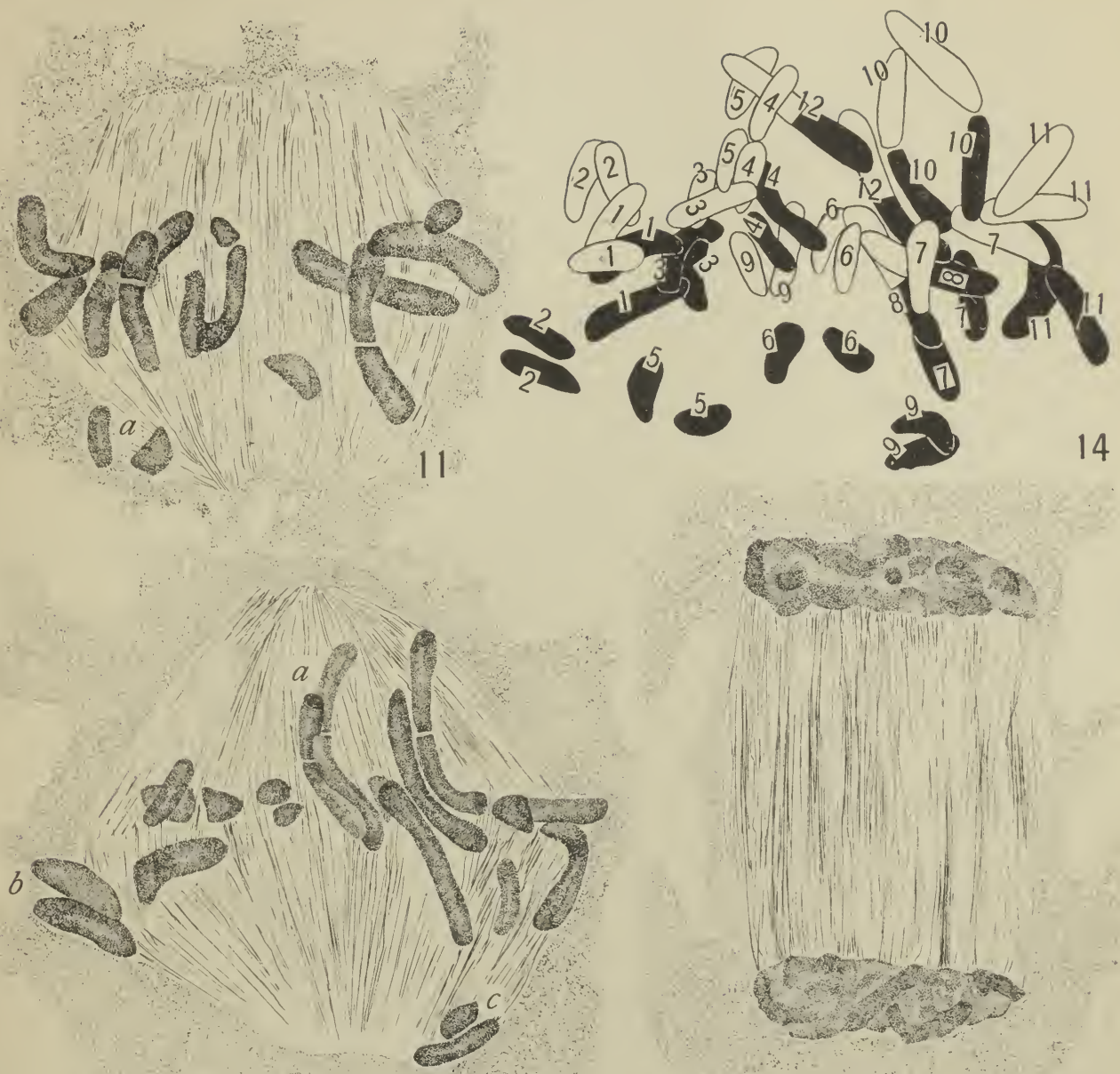

12
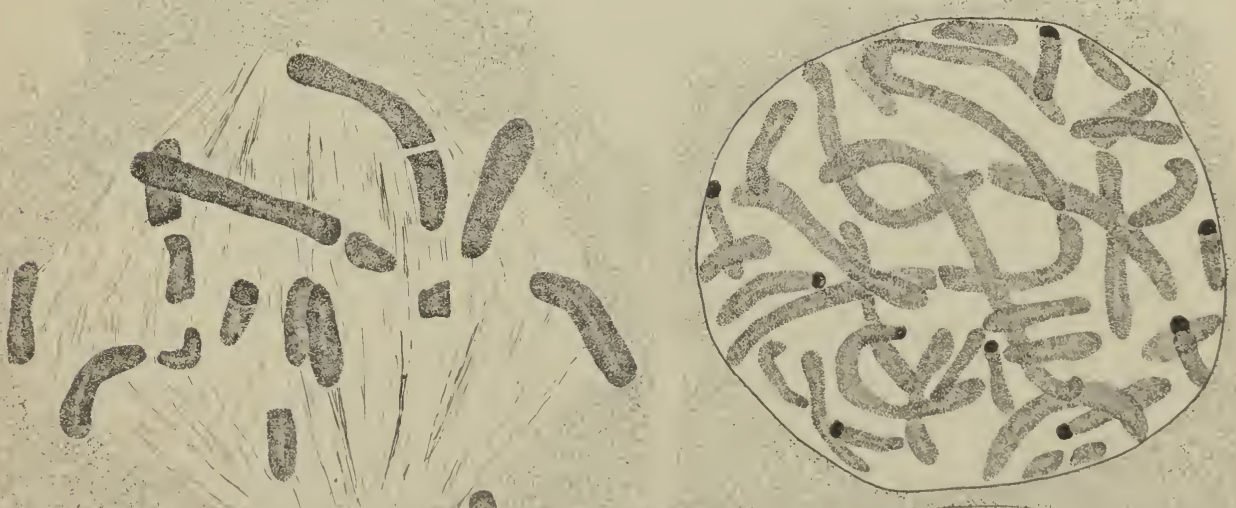

13 WW del. $\quad 16$ 



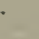




\section{โ \\ 30112072664698}

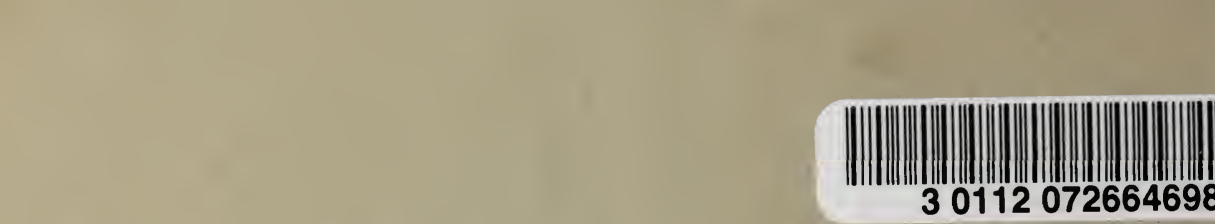

